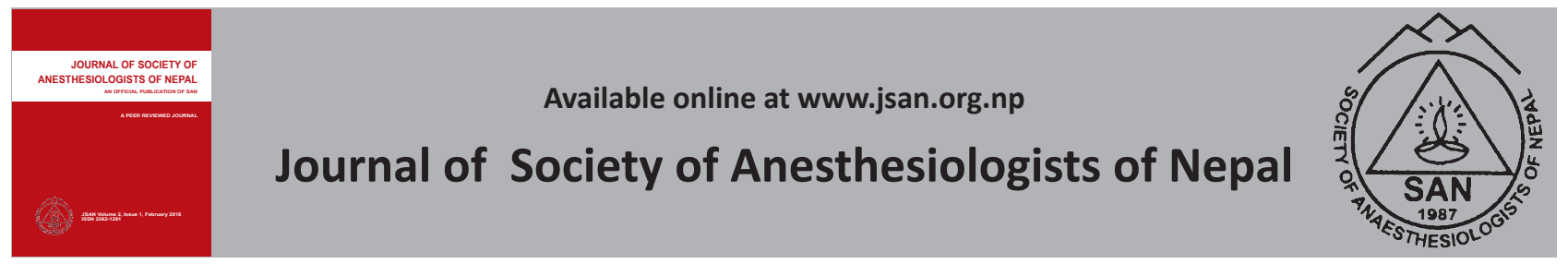

Case Report

\title{
Transillumination of palm for peripheral intravenous cannulation in an infant with difficult venous access
}

\author{
Gentle Sunder Shrestha, Binita Acharya, Sushil tamang
}

Tribhuvan University Teaching Hospital, Institute of Medicine, Maharajgunj, Kathmandu, Nepal.

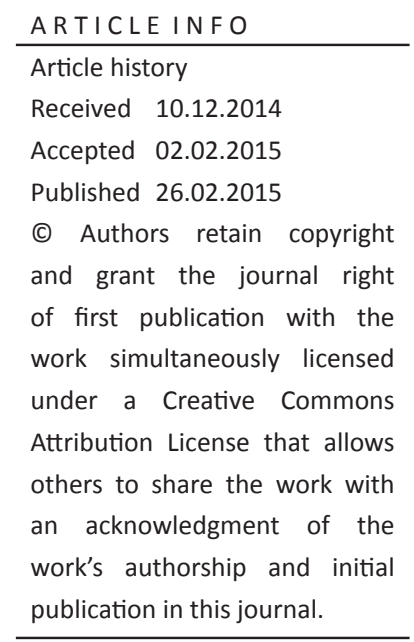

\begin{abstract}
Establishing venous access can be technically difficult in paediatric patients. Alternatives to intravenous access like central venous cannulation or venous cutdown carry a higher risk of complications. We report a case of successful intravenous access in an infant with anticipated difficulty, by performing transillumination of palm using a torch light.
\end{abstract}

Key Words: difficult peripheral venous catheterization; infant; transillumination.

How to cite this article: Shrestha GS. Transillumination of palm for peripheral intravenous cannulation in an infant with difficult venous access. JSAN 2015;2:31-33.

\section{Introduction}

Establishing peripheral intravenous access can be very challenging in infants and young children, even for the most skilled anaesthesiologist. ${ }^{1}$ Securing intravenous access is one of the ten golden rules of anaesthesia. Alternative solutions to peripheral intravenous cannulation like central venous cannulation and venous cutdown poses inherent risks for the patients. Central venous catheter placement is more difficult in childern than in adults. It is particulary challenging in neonates and infants. ${ }^{2}$ Difficult intravenous access can be predicted using difficult intravenous access
(DIVA) score (ranges from 0-10), which incorporates the parameters like visibility and palpability of vein after applying tourniquet, age and history of prematurity (Table 1.). ${ }^{3}$ The use of transillumination to facilitate venous access dates back to $1975 .{ }^{4}$ The light is absorbed by deoxygenated blood in the veins. Hence the veins are seen as dark lines within the illuminated areas. Studies using this technique have shown a high success rate of peripheral intravenous cannulation. ${ }^{5,6}$

Corresponding author:

Gentle Sunder Shrestha, MD

Department of Anaesthesiology and Critical Care

Institute of Medicine, Maharajgunj, Kathmandu, Nepal

Telephone +9779841288584

Email: gentlesunder@hotmail.com 
Table 1. Four-variable DIVA score:

Predictor Variable Score

\begin{tabular}{|c|c|c|c|}
\hline $\begin{array}{l}\text { Vein visible after } \\
\text { tourniquet }\end{array}$ & Visible, 0 & & $\begin{array}{l}\text { Not } \\
\text { visible, } 2\end{array}$ \\
\hline $\begin{array}{l}\text { Vein palpable } \\
\text { afer tourniquet }\end{array}$ & Palpable, 0 & & $\begin{array}{l}\text { Not } \\
\text { palpable, } \\
2\end{array}$ \\
\hline Age category & $\begin{array}{l}\geq 3 \text { years } \\
\text { old, } 0\end{array}$ & $\begin{array}{l}1-2 \text { years } \\
\text { old, } 1\end{array}$ & $\begin{array}{l}<1 \text { year } \\
\text { old, } 3\end{array}$ \\
\hline $\begin{array}{l}\text { History of } \\
\text { prematurity }\end{array}$ & $\begin{array}{l}\text { Not } \\
\text { premature, } \\
0\end{array}$ & & $\begin{array}{l}\text { Premature, } \\
3\end{array}$ \\
\hline
\end{tabular}

\section{Case report}

A six months old female infant, weighing seven kilograms, was planned for re-insertion of ventriculo-peritoneal shunt. She had the history of initial ventriculo-peritoneal shunt performed at the age of two months to manage hydrocephalus, that developed as a sequelae of meningitis. Her peripheral intravenous access was difficult during her previous surgery, mandating insertion of central venous catheter. Following her initial surgery, she had repeated hospital admission and intravenous antibiotic administration for shunt infection. This time, her peripheral veins were not visible or palpable even after application of torniquet. So, difficult peripheral intravenous access was anticipated.

After keeping nil per oral for 6 hours, intramuscular Ketamine $35 \mathrm{mg}$ and Atropine $0.07 \mathrm{mg}$ were administered to facilitate intravenous access. In the operating room, after attaching ECG and $\mathrm{SPO}_{2}$ monitor and after supplementing oxygen by face mask, tourniquet was applied over right forearm. Transillumination of the right palm was done with a bright torch light and all the ambient lights were turned off. Veins on the dorsum of the palm were clearly visible as dark lines and were successfully cannulated with $24 \mathrm{G}$ intravenous cannula at the first attempt. The cannula was flushed with $3 \mathrm{ml}$ of normal saline to confirm intravenous placement of catheter and to rule out paravenous leak. After observing no obvious swelling around the region of catheter tip, intravenous drip was attached to the cannula and anaesthesia \& surgery proceeded.

\section{Discussion}

Establishing intravenous access is a basic procedure in anaesthesia. Finding an accessible vein is frequenlty difficult in infants especially those with history of prolonged hospitalization, during which readily accessible veins have been exhausted. ${ }^{5}$ The scenario can be stressful and frustrating for an anaesthesiologist. DIVA score incorporates simple parameters to predict difficult intravenous access. ${ }^{3}$ The scoring system has been validated and the score of four or more is a predictor of difficult access. ${ }^{7}$ Our patient had the score of seven, which predicted difficult cannulation. Intramuscular Ketamine has been shown to be helpful to facilitate venous access in paediatric patients. ${ }^{8}$ So we administered Ketamine combined with Atropine to keep the child immobile, while maintaining patent airway.

Upper limb was chosen for cannulation as lower limb infusion is associated with increased incidence of thrombophlebitis and thrombosis. ${ }^{9}$ Various traditional methods have been described that can improve venous prominence for cannulation. Simple techniques like slapping of the skin overlying the vein, milking the vein from proximal to distal direction and use of proximal venous tourniquet can be effective. ${ }^{10}$ Use of betadine swabs is reported to be helpful in dark skinned patients. ${ }^{11}$

In pediatric patients, ultrasound guidance has been shown to be superior to traditional technique in difficult access patients. ${ }^{12}$ However, it is an operator dependent process and its use in resource constrained setup may not be feasible due to non-availability of ultrasound machine. ${ }^{10}$ In the absence of ultrasound machine, other techniques like immersing the limb in warm water ${ }^{10}$ and topical application of EMLA \& nitroglycerine ointment to attain venodilatation can be helpful. ${ }^{13}$

Transillumination for peripheral venous access in paediatric patients can enhance success, especially in patients with difficult access. ${ }^{1,5,6}$ It is mainly described for peripheral cannulation in hand and foot. ${ }^{6}$ Cold light source from fiberoptic cable, ${ }^{6}$ otoscope ${ }^{5}$ and commercially available Veinlite $^{1}$ can be used. Prolonged use of other light source that produce heat should be avoided to prevent burn. Here, we successfully cannulated the vein in the dorsum of hand using a bright torch light. We minimized the duration of exposure of light to avoid tissue heating.

Alternative tecnhiques like intraosseous access ${ }^{14}$ and peripheral venous cut-dow ${ }^{15}$ can be valuable in emergency situations when other measures fail, including in the event of paediatric cardiac arrest. The sequential algorithmic approach suggested by Mbamalu $D$ and colleagues can be clnically helpful. ${ }^{10}$ To include peripheral venous cut-down and ultrasound guided cannulation of great saphenous vein in the algorithm can be prudent. ${ }^{16}$

To conclude, transillumination of the palm can be a simple, yet effective technique to facilitate difficult peripheral intravenous cannulation in paediatric patients, thus avoiding the need and preventing the inherent risks of alternative tecnhiques for intravenous access.

\section{Acknowledgements: None}

Conflict of interest: none 


\section{References}

1. Girgis KK. Ultrasound guidance versus transillumination for peripheral intravenous cannulation in pediatric patients with difficult venous access. Egypt J Cardiothorac Anesth 2014;8:39-44.

2. Costello JM, Clapper TC, Wypij D. Minimizing compliations associated with percutaneous central venous catheter placement in children: Recent advances. Pediatr Crit Care Med 2013;14:273-83.

3. Yen K, Riegert A, Gorelick MH. Derivation of the DIVA score. A clinical prediction rule for the indentification of children with difficult intravenous access. Pediatr Emerg Care 2008;24:143-7.

4. Kuhns LR, Martin AJ, Gildersleeve S, Poznanski AK. Intense transillumination for infant veinpuncture. Radiology 1975;116:734-5.

5. Goren A, Laufer J, Yativ N, Kuint J, Ackon MB, Rubinshtein M, et al. Transillumination of the palm for veinpuncture in infants. Pediatr Emerg Care 2001;17:130-1.

6. Atalay $\mathrm{H}$, Erbay $\mathrm{H}$, Tomatir E, Serin S, Oner O. The use of transillumination for peripheral veinous access in paediatric anaesthesia. Eur J Anaesthesiol 2005;22:317-8.

7. O'Neill MB, Dillane M, Hanipah NFA. Validating the difficult intravenous access clinical prediction rule. Pediatr Emerg Care 2012;28:1314-6.

8. Denmark TK, Hargrove JR, Brown L. Intramuscular ketamine to facilitate pediatric central vascular access. CJEM 2004;6:259-62.

9. Tager IB, Ginsberg MB, Ellis SE, Walsh NE, Dupont I, Simchen E, et al. An epidemiological study of the risks associated with peripheral venous catheters. Am J Epidemiol 1983;118:839-51.

10. Mbamalu D, Banerjee A. Methods of obtaining peripheral venous access in difficult situations. Postgrad Med J 1999;75:459-62.

11. Bhende MS. Venepuncture and peripheral venous access. In: Henreting FM, King C, eds, Textbook of paediatric emergency procedures. Baltimore: Williams \& Wilkins, 1997; 803.

12. Doniger SJ, Ishimine P, Fox JC, Kanegaye JT. Randomized controlled trial of ultrasound-guided peripheral intravenous catheter placement versus traditional techniques in difficult-access pediatric patients. Pediatr Emerg Care 2009;25:154-9.

13. Michael A, Andrew M. The application of EMLA and glyceryl trinitrate ointment prior to venepuncture. Anaesth Intensive Care 1996;24:360-4.

14. Kleinman ME, Chameides L, Schexnayder SM, Samson RA, Hazinski MF, Atkins DL, et al. Part 14: Pediatric advanced life support: 2010 American Heart Association Guidelines for Cardiopulmonary Resuscitation and Emergency Cardiovascular Care. Circulation 2010;122:S876-S908.

15. Kissoon N, Frewen TC. Pediatric venous cutdowns: utility in emergency situations. Pediatr Emerg Care 1987;3:218.

16. Triffterer L, Mahofer P, Willschke H, Machata AM, Reichel G, Benkoe $T$, et al. Ultrasound-guided cannulation of the great saphenous vein at the ankle in infants. Br J Anaesth 2012;108:290-4. 